\title{
Participation in contact or collision sports in athletes with epilepsy, genetic risk factors, structural brain lesions, or history of craniotomy
}

\author{
Vincent J. Miele, M.D., Julian E. Bailes, M.D., and Neil A. Martin, M.D. \\ Department of Neurosurgery, West Virginia University School of Medicine, Morgantown, \\ West Virginia; and Division of Neurosurgery, University of California Los Angeles \\ School of Medicine, Los Angeles, California
}

\begin{abstract}
$\checkmark$ Despite a plethora of guidelines for return to play following mild head injury, a discussion of when and if an athlete should be allowed to participate in contact or collision sports if he or she sustains a structural brain lesion or after a head injury requiring craniotomy is lacking. The structural lesions discussed include arachnoid cyst, Chiari malformation Type I, cavum septum pellucidum, and the presence of ventriculoperitoneal shunts. Issues unique to this population with respect to the possibility of increased risk of head injury are addressed. The population of athletes with epilepsy and certain genetic risk factors is also discussed. Finally, the ability of athletes to participate in contact or collision sports after undergoing craniotomies for traumatic or congenital abnormalities is evaluated. Several known instances of athletes returning to contact sports following craniotomy are also reviewed.
\end{abstract}

\author{
KEY WORDS • brain lesion • arachnoid cyst • cavum septum pellucidum • \\ Chiari malformation - craniotomy • epilepsy - genetic risk factor • \\ ventriculoperitoneal shunt $\bullet$ sports medicine
}

A PPROXIMATELY $20 \%$ of the 1.54 million head injuries that are estimated to occur in the US each year are sports related. ${ }^{71}$ Advances in diagnosis and management over the past decade have resulted in a plethora of guidelines for return to play after mild head injury. Although these systems address in detail the treatment of an athlete after concussion, discussion of when and if an athlete should be allowed to participate in contact or collision sports following discovery of a structural brain lesion or after a head injury requiring craniotomy is lacking.

In this article we address participation issues in athletes with structural brain lesions or with a history of craniotomy. The structural lesions we discuss include arachnoid cyst, CM-I, cavum septum pellucidum, and the presence of a VP shunt. Issues unique to this population with respect to the possibility of increased risk of head injury are addressed. The athletic population with epilepsy and certain genetic risk factors is also discussed. Finally, the ability of athletes to participate in contact or collision sports after undergoing craniotomies for traumatic or congenital abnormalities is evaluated. There are several known instances of athletes returning to contact sports postcraniotomy, and these cases are reviewed.

Abbreviations used in this paper: $\mathrm{APOE}=$ apolipoprotein $\mathrm{E}$; CM-I = Chiari malformation Type I; CSF = cerebrospinal fluid; $\mathrm{MR}=$ magnetic resonance; $\mathrm{SDH}=$ subdural hematoma; $\mathrm{TBI}=$ traumatic brain injury; $\mathrm{VP}=$ ventriculoperitoneal.

\begin{abstract}
Structural Brain Lesions
Arachnoid Cyst

Arachnoid cysts result from developmental splitting of the arachnoid membrane ${ }^{73}$ and are often incidentally diagnosed in childhood. Found more commonly in male patients younger than 20 years of age, they are present in $1 \%$ of the general population. Although they are considered to be benign developmental anomalies, and asymptomatic athletes who harbor them have ordinarily been allowed to continue to participate in contact sports, arachnoid cysts have been associated with a triad of complications, including midline shift, SDH, and intracystic hemorrhage. ${ }^{25,73}$ The rare but well-known propensity for arachnoid cysts to hemorrhage, either spontaneously or as a result of trauma, is thought to occur in approximately $0.1 \%$ of people with this entity.

The relationship between arachnoid cysts and SDHs was first noted in $1971 .{ }^{66}$ Since that time, an association between the presence of an arachnoid cyst and the later development of an SDH has been identified in several contact and collision sports, including soccer (caused by "heading" the ball), ${ }^{41,62,78}$ football, ${ }^{81}$ and basketball. ${ }^{42}$ This complication has also been seen in noncontact sports such as race walking. ${ }^{15}$

Several theories exist to explain why arachnoid cysts are linked to a higher risk of hemorrhage. Bleeding is thought to originate from fragile vessels within the cyst wall or leptomeninges, or from bridging veins..$^{58}$ Because
\end{abstract}


the cysts are less compliant than normal brain tissue, a reduction in buffering of adjacent tissue results in an increased likelihood of tearing of associated bridging vessels. It is also possible that the different composition of arachnoid cyst fluid compared with normal CSF results in magnification and a greater transfer of pressure generated by head impacts, increasing the likelihood of rupture of the bridging veins or of the vessels within the cyst wall. ${ }^{25}$

An arachnoid cyst may present an increased risk, and although it is not an absolute contraindication to participation in contact sports, patients and their family members should be carefully counseled that the risk of a traumatically induced hemorrhage is present but uncertain.

\section{Chiari Malformation Type I}

The CM-I is a congenital disorder with an unknown incidence characterized by the caudal herniation of cerebellar tonsils through the foramen magnum. This is an increasingly recognized finding on MR imaging, with a mean age at onset of symptoms and diagnosis of $25 \pm 15$ years, which overlaps with the most common years of participation in contact and/or collision sports. The variable clinical symptoms result from brainstem compression by the herniating tonsils and from disorders of CSF circulation. ${ }^{52}$ Classic symptoms are severe throbbing headache and neck pain, starting shortly after coughing, sneezing, straining, changing posture, or physical exertion. Because symptoms may be provoked by increased intracranial pressure, ${ }^{49}$ it has been questioned whether the presence of a CM-I may alter the normal CSF capacity for buffering the brain in instances of high-velocity impacts. ${ }^{6}$ Although this is of no apparent consequence during normal activities, this abnormality may prevent the normal buoyancy of the CSF from safely protecting the brain from the strong forces that can be generated during impact in contact sports.

Numerous football players at the high school and college levels who sustained concussions were later found to have CM-Is as their only abnormality on radiographic evaluations. ${ }^{5}$ Whether these findings are incidental or the CM-I was a contributing factor to their injury is a subject of debate. Also of concern is the rare fatality associated with the condition; several cases of sudden cardiorespiratory arrest in children with no prior neurological abnormalities have been reported. ${ }^{50,77}$ Cardiac arrest has also been described following a brisk head movement in an adult with a CM-I, ${ }^{1}$ as have been deaths following minor head trauma in two adults (it is likely that these fatalities were the result of respiratory arrest). ${ }^{82}$ This could be the result of medullary compression from the cerebellar tonsillar herniation, which may have depressed the function of the respiratory center, producing hypoxia. ${ }^{83}$ "Drop attacks," one of the features of basilar migraine, are also one of the uncommon manifestations of CM-I, having been reported in 2 to $3 \%$ of patients in recent series. ${ }^{27,59,74}$ These attacks also seem to be related to compression of the medulla caused by temporarily increased tonsillar herniation.

At present, a CM-I per se seems to be more of a relative than an absolute contraindication to further participation in contact sports in asymptomatic patients. In those in whom this abnormality was discovered during a diagnostic evaluation for concussion, we have generally reacted conservatively and recommended against a return to con- tact sports. Refraining from contact sports has been recommended in patients who harbor CM-I with associated syringomyelia, obliteration of the subarachnoid space, or indentation of the anterior medulla. ${ }^{11}$ Additionally, the presence of a CM-I that is symptomatic should contraindicate participation in contact or collision sports.

\section{Cavum Septum Pellucidum}

The septum pellucidum consists of two leaves of glial tissue that are usually fused or contiguous in adults. If they remain separated, then the anterior closed space between them is known as a cavum septum pellucidum. The actual incidence of this entity in the general population at any time after the neonatal period has a wide reported incidence range (3-60\%). ${ }^{22,51,69}$

Although its presence is a common and usually incidental finding on neuroimaging or neuropathological studies, an association of the cavum septum pellucidum with boxers was first noted incidentally in $1962 .{ }^{72}$ The condition has been repeatedly associated with chronic TBI in boxing, on the basis of neuroimaging or postmortem studies. It is likely that a cavum septum pellucidum in boxers is acquired rather than being congenital and results from rotational injuries that lead to tearing and separation of the septum pellucidum. ${ }^{51}$ It has also been implicated in other types of brain trauma, such as those sustained in fatal road traffic accidents. ${ }^{61}$

Importantly, the cavum septum pellucidum abnormality discussed in neuropathological studies as pointing to dementia pugilistica is fenestrated as well as being associated with forniceal abnormalities. A cavum septum pellucidum with intact walls is not a diagnostic finding of this condition. ${ }^{51}$ Additionally, there is no evidence that this entity necessarily correlates with neuropsychological or clinical abnormalities. The presence of an isolated cavum septum pellucidum is unlikely to be of clinical importance and should not preclude an athlete from participation in contact or collision sports. It has been reported that the morphological features of this entity may vary between examinations. ${ }^{84}$ The development or serial enlargement of a cavum septum pellucidum could be evidence of the early development of chronic brain damage or dementia pugilistica, particularly if associated with other evidence of neurological deficit.

\section{Ventriculoperitoneal Shunts}

A significant improvement in the prognosis for children in whom shunts have been placed to treat hydrocephalus has been made during the past 20 years, and a considerable percentage of this population attains high levels of neurological functioning and is able to participate in organized sports. ${ }^{9,10,16}$ The estimated prevalence of VP shunts is 125,000 in the US. ${ }^{8}$ The medical literature contains few articles that specifically address the issue of sports-related shunt complications. ${ }^{7}$ Additionally, a recent review of the legal literature was performed and failed to produce any cases of sports-related shunt complications.

There are several reasons why this population is thought to be at a higher risk for neurological sequelae during participation in sports. Some of these patients have persistent ventriculomegaly despite shunt placement. These athletes may be at risk for cortical collapse over their enlarged 
ventricles, with secondary tearing of bridging veins and development of SDHs. ${ }^{7}$ Patients who have had longstanding hydrocephalus sometimes have a thinner cranium. This could increase the risk to the participant for brain injury from impacts to the head. The physiological reserve of the central nervous system to respond to injury may be significantly reduced in this population due to the original insult that caused the hydrocephalus. The CSF acts in part as a shock absorber for the brain. Patients who have undergone shunt placement for hydrocephalus have a change in the dynamics of the CSF flow that could have a negative impact on this buffering effect.

A survey of the Joint Section on Pediatric Neurosurgery of the American Association of Neurological Surgeons and the Congress of Neurological Surgeons was recently published. ${ }^{7}$ This survey revealed a very low incidence of sports-related problems with VP shunts; the incidence of sports-related shunt complications was significantly less than $1 \%$. None of these instances were reported to have caused a neurological morbidity or a fatality. The most commonly described issues were shunt fractures and shunt dysfunction occurring close in time to participation in an active sport. The catheters of the currently used systems can become calcified along their tracks over time and may become adherent to adjacent tissue. This may increase the risk of fracture or disconnection of the catheter during participation in sports. Dysfunction of the shunt caused by a sports-related fall directly onto the shunt valve has been reported. The sporting events most frequently implicated by providers were wrestling and soccer. Three providers specifically indicated that the observed adverse event could be attributed to supervised wrestling. All such events involved catheter disconnections or fractures. Accumulation of a clot or other subdural fluid collection was reported by four providers. Three of these involved subacute subdural fluid accumulations in patients with enlarged ventricles, and one acute clot was reported that occurred in an athlete with normal-sized ventricles who directly headed a fast-traveling soccer ball. Football, turning cartwheels, rapid somersaulting, and sledding or tobogganing were also linked to adverse effects. Overall, this report established that the incidence of observed problems attributable to sport participation in shunt-treated children seems very low.

Currently, there are no guidelines for allowable activities or contact sport restrictions in this population. The majority $(89 \%)$ of surveyed neurosurgeons do not restrict participation in noncontact sports, and one third of responding neurosurgeons do not restrict participation in contact sports. Another third of responding neurosurgeons prohibit or strongly advise against participation in all contact sports. Football was the most commonly prohibited sport, yet data from this survey did not implicate football-related problems in children treated with shunts. This could be the result of a low incidence of football participation in these children or of improved protective equipment. Boxing and wrestling were also specifically prohibited.

\section{Epilepsy}

Epilepsy affects approximately $2 \%$ of the population, ${ }^{37}$ and the attitudes toward participation of this population in contact sports have changed over the years, from avoid- ance to encouragement. Several issues are unique to individuals with epilepsy. It is conceivable that exercise could exacerbate seizures either directly, through hyperventilation, or indirectly, by alteration of the levels of anticonvulsant drugs. Trauma from contact or collision sports resulting in recurrent minor head injuries could worsen epilepsy. These risks are theoretical for the most part, and very few case reports support these notions. It has become increasingly clear that a more reasoned approach is to individualize the decision for each sport and each patient based on a risk-benefit analysis, which leads to few restrictions overall.

Although it is possible that the occurrence of a seizure during certain athletic events could cause a substantial increase in risk to the participant, this pertains more to sports involving heights, such as gymnastics or horseback riding. ${ }^{37}$ Some types of seizures could leave a patient vulnerable from lack of attention to impending injury, as in being blind-sided during football. ${ }^{30}$ Therefore, when considering if an athlete with epilepsy should participate in contact or collision sports, one consideration is the type of seizure disorder the athlete suffers from. Generalized tonic-clonic (grand mal) seizures may result in unprotected falling. This is especially true with atonic seizures that result in a sudden loss of muscle tone. Seizures characterized by unprotected falling put patients continually at risk of injury from striking the playing surface or another object. Athletes suffering absence seizures consisting of brief (typically 3-10 seconds), motionless, nondistractible staring usually maintain their balance. This condition places the participant at an increased potential risk of injury from being unable to protect him- or herself during contact sports. Simple partial seizures often do not affect consciousness. Therefore, this type of seizure is unlikely to result in injury as a result of unanticipated falls or unprotected blows during participation. Complex partial seizures often do result in an alteration but not a loss of consciousness, and usually are 1 to 2 minutes in duration, followed by a brief period of confusion. Unlike players who suffer generalized seizures, athletes with complex partial seizures are often amnestic to the event, and it may go unnoticed until abnormal behavior is observed, such as wandering around the playing field. Although complex partial seizures are similar to absence seizures in that they may involve only staring, the duration is much longer, which theoretically increases the athletes' exposure to injury from an inability to protect themselves. ${ }^{30}$ Obviously, seizures that begin as partial ones may generalize, with the same specific risks as for primary generalized seizures noted earlier.

One of the strongest arguments for disallowing participation in contact or collision sports is that the multiple minor head traumas associated with such participation could exacerbate the condition. There is only one report of seizures caused by blows to the head ${ }^{19}$ and no evidence that contact sports are harmful for most patients with epilepsy. ${ }^{4}$ It is also theoretically possible that repeated or severe head injury sustained during contact sports could exacerbate seizures in a patient known to have epilepsy, an argument that initially led to complete prohibition of participation in sports for this group. ${ }^{30}$ Although evidence does exist that head injury can cause epilepsy, this association only holds true for severe traumas..$^{2,3,45-47}$ There is no 
consistent report of increased risk of subsequent epilepsy from a typical mild head injury in the general population. Typical sports-related head injuries are so mild that they are extremely unlikely to be associated with epilepsy.

Numerous factors have been discussed that could cause this increase in seizure frequency and/or severity, including repeated head trauma, aerobic exercise, hyperventilation, physical and psychological stress, and changes in antiepileptic drug metabolism. ${ }^{30}$ Fear that increasing aerobic exercise may exacerbate seizures was magnified by several case reports of patients whose seizures were "triggered" by exercise..$^{53,55,57,68}$ Because hyperventilation has been shown to trigger absence seizures when performed at rest during a routine electroencephalography study, it was extrapolated that seizures could also be triggered during exercise-induced hyperventilation. Differences in the physiology of resting compared with exercise-induced hyperventilation make this unlikely. Increased metabolic demand during exercise is the cause of increased respiratory effort, a compensatory response to avoid hypercapnia. This is in contrast to the hypocapnia induced by resting hyperventilation that results in cerebral vasoconstriction. This promotes alkalosis and can make absencerelated abnormalities found on electroencephalography studies more pronounced. Because the increased respiratory effort during exercise is a response to acidosis, it has the opposite effect of causing the relative suppression of abnormalities seen on electroencephalography. In fact, exercise-induced hyperventilation may even produce a refractory period that can delay the activating effects of resting hyperventilation. ${ }^{29,34}$ The current thinking is that, although exercise does initiate exacerbation of seizures in rare cases, on average it reduces seizure frequency during prospective formal evaluation. ${ }^{28,54}$ In fact, interictal epileptiform activities remained unchanged or decreased during or immediately after exercise in the majority of patients studied, even in some patients with exercise-associated seizures..$^{29,34,55}$ Additionally, because of the general health and psychological benefits of aerobic exercise, it is recommended for most patients, although it must be recognized that this type of exercise will trigger seizures in some.

An additional consideration in this population is the effect of exercise on drug metabolism. It is well known that exercise induces hepatic microsomal enzymes. This can result in an increase in medication clearance, requiring a dose adjustment to maintain efficacy ${ }^{26,31}$ In addition, the release of fatty acids may compete for protein binding sites and displace anticonvulsant medications, leading to a higher free fraction of highly protein-bound drugs. ${ }^{30}$

Current opinion is that participation in contact or collision sports benefits individuals with epilepsy in many ways, including improvements in seizure control, mood, and quality of life. Contact sports such as football, hockey, and soccer have not been shown to induce seizures, and athletes with epilepsy should not be prohibited from participation. ${ }^{37}$ There is little evidence to justify summarily excluding patients with epilepsy from most sports, but some commonsense rules apply. ${ }^{13,30,33,80}$ Obviously, care must be taken in sports involving heights, such as gymnastics, ${ }^{37}$ and athletes with epilepsy must be evaluated on an individual basis; however, no significant evidence exists to suggest that contact sports are harmful to these individuals.

\section{Genetic Risk Factors}

With the completion of the human genome map, our understanding of the influence of molecular biology on an athlete's ability and susceptibility to injury is expanding. More than 900 genetic tests are available (Appendix); many could have applications in athletes. The best-known susceptibility gene for head injury is $A P O E^{*} E 4$.

Apolipoprotein $\mathrm{E}$ is important for lipoprotein transport and cholesterol homeostasis by its promotion of the recognition and catabolism of APOE-containing lipoproteins (for example, $\beta$-very-low-density lipoprotein, very-lowdensity lipoprotein, intermediate-density lipoprotein, and high-density lipoprotein) by the low-density lipoprotein receptors, the E/ $\alpha 2 \mathrm{M}$ receptor LRP1, gp330/megalin, and the very-low-density lipoprotein receptor. It is synthesized predominantly by astrocytes and microglia and thus is highly expressed in the brain. The APOE gene, located on chromosome 19, occurs in three common allelic forms, $A P O E^{*} E 2$, $* E 3$, and $* E 4 .{ }^{44}$ In several studies the $A P O E^{*} E 4$ allele has been linked to poor outcomes following TBI. ${ }^{18,23,32,39,43,48,70,75}$

Attention was first focused on this gene when it was linked to late-onset familial and sporadic Alzheimer disease. ${ }^{21,67}$ The neuropathological similarities between chronic TBI and Alzheimer disease led to the discovery of the possible link between sports-related brain injury and $A P O E^{*} E 4.22,24,64,76,79$ Chronic TBI is a worrisome complication of contact or collision sports during which the participant sustains repetitive blows of variable force to the head. In 1997, a study performed in 30 boxers revealed that those with the $A P O E^{*} E 4$ gene and high exposure to the sport were at an increased risk of neurological dysfunction compared with those without the gene. In this study it was also found that all of the boxers in whom severe neurological impairment developed possessed the $A P O E^{*} E 4$ allele..$^{39}$ The association between this gene and a higher risk of chronic TBI was strengthened by a second study performed in 1997 in a nonboxing population of patients who had suffered a neurotrauma. ${ }^{75}$

The pathophysiological mechanism for this association may be that $\beta$-amyloid is deposited in the brain to a greater extent after head trauma in individuals with the ${ }^{*} E 4$ allele. ${ }^{35,56,65}$ The allele may also affect the efficiency of neuronal repair, which is suggested by the poorer outgrowth of neurites observed in cell cultures containing $A P O E^{*} E 4^{60}$ after traumatic injury, which could lead to the accumulation of residual tissue damage after repeated episodes of trauma. ${ }^{40}$ The presence of $A P O E^{*} E 4$-related alterations in the neuronal cytoskeleton, increased susceptibility to reactive oxygen species in association with $A P O E^{*} E 4$, and altered intracerebral cholesterol trafficking are other mechanisms proposed to be the cause of increased susceptibility to chronic TBI in the athlete with the $A P O E^{*} E 4$ gene. ${ }^{44}$

The link between $A P O E * E 4$ and chronic TBI is not universally accepted. Most studies relating to mild TBI in sports have included a relatively small population of patients, and this has been a major criticism. In addition, investigators have relied on brief cognitive assessments or coarse measures of global functioning, thereby limiting their conclusions. In other prospective studies on the role of the $A P O E^{*} E 4$ allele in mild to moderate brain injury in 
which a more detailed evaluation of neuropsychiatric outcome was performed, no association was found between the presence of the $A P O E^{*} E 4$ allele and poor outcome across all measures. ${ }^{17}$

The relationship between this gene and an increased risk of chronic TBI has major implications. Should all athletes in contact or collision sports be tested for $A P O E^{*} E 4$ as a part of a preparticipation physical; and should those with positive results be banned from participation? The genetic profile of an athlete could be useful in determining if the participant is predisposed to a particular injury. If this information is known before participation, the athlete could be properly counseled concerning his or her risks, given special techniques and equipment to minimize risk, and offered alternative sporting activities. On the other hand, several social concerns exist with regard to DNA-based testing. When testing is performed, who should be allowed to have access to the acquired information? Should sports regulatory agencies have access to information on an individual's $A P O E^{*} E 4$ status before granting a boxing license? If an individual is discovered to carry a less than desirable gene for a specific sport, how would it affect his or her ability to participate psychologically, and will this information create a new form of discrimination? Should parents, coaches, and even sports agents be allowed to request genetic testing on minors and/or clients? If genes and gene therapies are allowed to be patented, will this limit accessibility and create unfair advantages between athletes?

The time may come when biotechnology firms buy the rights to sports stars' genetic codes. If the prescreening of fetuses occurs, how can selective terminations of pregnancies be prevented if less-than-ideal genetic markers are discovered by parents and/or governments seeking highperformance athletes? Will managers and agents be allowed to see an athlete's genetic profile before they sign an athlete to a contract or agree to train him or her? These profiles could potentially be used to weed out athletes who are predisposed to injury or who have a limited ability to perform. The Americans with Disabilities Act, which was signed into law in 1990, made it illegal to discriminate against disabled workers. The Federal Equal Employment Opportunity Commission has ruled that this act also protects people from discrimination on the basis of their genetic profile.

Because the connection between the $A P O E^{*} E 4$ gene and sports-related head injury is still not decided, discussion of these ethical and legal issues seems somewhat premature. Nevertheless, although these quandaries seem distant, the current rate of growth in the field of genetics demands that these ethical and legal issues be evaluated now. To address these concerns, the National Center for Human Genome Research, the National Institutes of Health, and the Human Genome Program of the Department of Energy have established the Joint Working Group on Ethical, Legal, and Social Issues associated with mapping and sequencing the human genome. This group is currently developing policy recommendations for the necessary protections that must be put in place as new genetic tests are developed.

\section{Craniotomy}

The safety of allowing the return of an athlete to a con- tact or collision sport following craniotomy has long been debated in neurosurgical and sports medicine circles, and a conservative approach has generally been taken in the past. There have been no controlled studies or patient series on which to base recommendations. In general, there are three primary apprehensions relative to the inherent safety of the cranium to withstand impacts in the postoperative period. These consist of concerns about the strength of the craniotomy flap to withstand direct pressure from blows to the head; the potential fragility of the tissue at the operative site and neovascularity from the healing process; and the alteration of the normal CSF pathways, which will potentially alter the normal "buoyancy" of the brain.

The healing of a craniotomy flap, that is, the integration of the island of bone that has been removed and then restored, occurs circumferentially across the kerf line. This line represents the amount of bone removed by the craniotome. A commonly used criterion in this population is that radiographically demonstrated partial or complete healing of the bone flap must be present as a prerequisite before the athlete can return to play. ${ }^{5}$ This commonly occurs within 1 year in nonsmokers. No standardized studies are available in which the effectiveness of newer cranial reconstruction plates at rigid fixation has been evaluated. Similarly, no standardized studies are available to determine the contribution of the recently introduced bone matrix products to more rapid and secure healing of the craniotomy flap.

There are healing and fibrotic reactions that occur after any surgical procedure, and the brain, dura mater, and overlying skull and scalp also display a normal pattern of closure and regrowth at the site of excision and the procedure. Although fragility is an inherent concern, it does not appear that there is any unusual or particular aspect to this area that would be prohibitive for safe return to contact or collision sports.

The brain is suspended within the cranium by extensive CSF distribution throughout the subarachnoid space. This space can be focally altered by surgical interventions that lead to scarring and possible restrictions of normal flow and buoyancy. Significant intracranial hemorrhage or parenchymal injury can obliterate the normal CSF pathways by producing scarring. Theoretically, this could affect the brain's buoyancy and result in a loss of cushioning effect, increasing the patient's vulnerability to subsequent injury. Unfortunately, no studies exist regarding scarring of the CSF pathways and consequent decreased buoyancy of the brain and increased susceptibility to concussive forces.

\section{Documented Returns to Contact or Collision Sports Postcraniotomy}

Professional Ice Hockey. A professional hockey player, who had sustained a parenchymal hemorrhage, underwent successful surgery to remove a temporal arteriovenous malformation. He returned to play competitively for several years without sequelae. In addition, fractures of the frontal sinus anterior or posterior wall are known to have occurred in both soccer and ice hockey players who subsequently returned to participation in their respective sport. ${ }^{63}$

Professional Boxing. The return of athletes to the sport of professional boxing at the elite level after craniotomy has been documented. ${ }^{36,38}$ Marco Antonio Barrera, one of 
the best featherweight professional boxers in the world, began to complain of headaches in 1995. In 1997, a neurosurgeon in Mexico City examined him and discovered a cavernous angioma, which was repaired on August 29, 1997. Barrera participated in 16 matches after the surgery, until it became public just weeks before a bout in San Antonio. After numerous examinations and imaging studies, the Texas Boxing Commission gave Barrera permission to participate.

If an athlete is barred from competition in the US, he or she may choose to participate outside of this country. This occurred recently after a boxer (Edwin Valero) was suspended for an abnormality discovered on MR images obtained after he suffered a brain trauma. Venezuelan Boxing Federation medical records indicate that a hematoma was detected in Valero's head and was removed using a drainage procedure. The athlete was then suspended by the New York State Athletic Commission and the Association of Boxing Commissions from competing in the US. ${ }^{20}$ After being cleared by doctors in Argentina, Valero resumed his career in the ring outside of the US.

Amateur Soccer. A healthy 16-year-old girl presented with occipital headaches and numbness of the right face and body that had lasted 4 days. Results of a neurological examination were normal. One month previously, a soccer ball had struck her with significant force on the left side of the head. She did not lose consciousness at the time, but she experienced a period of transient disorientation and did not interrupt her play. There was no apparent amnesia. A cranial computed tomography scan revealed a left middle fossa extraaxial hyperdense lesion in the region of the sylvian fissure without a mass effect. In addition, MR imaging revealed a 20-mm-thick chronic SDH in the left frontotemporal convexity in communication with the arachnoid cyst and causing a mass effect. A left temporal craniotomy $3 \mathrm{~cm}$ in diameter revealed an arachnoid cyst in the sylvian fissure with a solid clot and subacute subdural fluid, which was drained along with the large chronic SDH. After drainage of the hematoma and fenestration of the cyst wall, underlying poorly developed frontal and temporal opercula consistent with a chronic arachnoid cyst were observed. After a watertight dural closure was performed, the bone flap was resecured rigidly with titanium plates. The patient did well postoperatively and has remained asymptomatic. A follow-up computed tomography scan obtained 1 month postsurgery demonstrated complete resolution of the chronic SDH and persistent hypodensity in the region of the cyst. Neuroimaging studies obtained the following year demonstrated healing of the kerf lines of the craniotomy, and the athlete was allowed to return to participation and has done so without incident. ${ }^{62}$

Professional Football. A 20-year-old man who played National Collegiate Athletic Association Division I football began to have headaches and feelings of depersonalization. Progression of these symptoms ultimately led to neuroimaging studies, which demonstrated a large right frontotemporal arachnoid cyst. This cyst was successfully removed, and fenestration to the subarachnoid space was performed as well. The following year, 9 months after his craniotomy, he returned to the team for his senior year, in which time he gained 1100 yards and scored 14 touch- downs. He had a brief career in the National Football League, which included scoring two touchdowns. Although he sustained a cerebral concussion at the professional level, it was believed by the athlete-as well as being supported by the results of medical evaluation - that he successfully reentered the sport without direct consequences resulting from his craniotomy.

As recommended in current return-to-play guidelines, athletes who remain symptomatic, with or without provocative testing, should not be allowed to participate until all of these symptoms have completely resolved. ${ }^{14}$ Injuries that result in permanent central neurological sequelae should contraindicate a return to contact or collision sports. It has also been suggested that symptomatic neurological or pain-producing abnormalities around the foramen magnum should disallow return to play. ${ }^{12}$ Injuries that result in damage to the underlying brain parenchyma and spontaneous subarachnoid hemorrhage from any cause should contraindicate return.

The advisability of allowing athletes to reenter the competitive arena of contact sports after undergoing a craniotomy remains unclear. We commonly discourage return to contact sports in athletes who have suffered parenchymal injuries that required a craniotomy, based solely on experience. We have recently considered rigid cranial fixation not to be an absolute contraindication to later participation in contact sports in an athlete with normal results on neurological examination. We believe that the newer cranial reconstruction plates may confer a major advantage in terms of rigid fixation and the promotion of osteoblastic bridging of the kerf lines in the craniotomy. Similarly, although no standardized studies are available, we believe that the recently introduced bone matrix products may contribute to more rapid and secure healing of the craniotomy flap.

\section{Conclusions}

With advances in the diagnosis and management of sports-related head injuries, participation guidelines continue to evolve as our understanding of various conditions improves. Formerly, structural brain lesions were considered to be absolute contraindications to participation in contact or collision sports. These decisions were for the most part based on the opinions of the physicians involved, who wanted to err on the side of caution. Recent increases in appreciation of the health benefits of sports participation as well as the growing financial rewards for the professional athlete have led to a rethinking of these situations. With the large salary that is possible today for the professional athlete, it is difficult to defend ending a career by arguing that the athlete is at an increased risk of injury when no data exist to support this claim. Obviously, more research is essential to objectify with solid data the reasoning behind ending an athlete's career and possibly his or her only source of income. Thus, athletes with epilepsy, genetic risk factors, structural brain lesions, or a history of craniotomy are often now allowed, with appropriate observation and precautions, to participate in sports formerly denied them. 


\section{Appendix}

Currently available DNA-based gene tests for neurological disorders

amyotrophic lateral sclerosis

Alzheimer disease ataxia telangiectasia

Charcot-Marie-Tooth disease

Duchenne muscular dystrophy

Huntington disease

Tay-Sachs disease

spinal muscular atrophy

fragile $\mathrm{X}$ syndrome

spinocerebellar ataxia

Angelman syndrome

neurofibromatosis Type 1

Prader Willi syndrome

myotonic dystrophy

Becker muscular dystrophy

\section{References}

1. Alegre S, García-Rubira JC, Patrignani G: Cardiac arrest in a 31-year-old man because of the Arnold-Chiari malformation. Int J Cardiol 46:286-288, 1994

2. Annegers JF, Grabow JD, Groover RV, Laws ER Jr, Elveback LR, Kurland LT: Seizures after head trauma: a population study. Neurology 30:683-689, 1980

3. Annegers JF, Hauser WA, Coan SP, Rocca WA: A populationbased study of seizures after traumatic brain injuries. N Engl J Med 338:20-24, 1998

4. Arida RM, de Jesus Vieira A, Cavalheiro EA: Effect of physical exercise on kindling development. Epilepsy Res 30: 127-132, 1998

5. Bailes JE, Cantu RC: Head injury in athletes. Neurosurgery 48:26-46, 2001

6. Beuls EA, Vandersteen MA, Vanormelingen LM, Adriaensens PJ, Freling G, Herpers MJ, et al: Deformation of the cervicomedullary junction and spinal cord in a surgically treated adult Chiari I hindbrain hernia associated with syringomyelia: a magnetic resonance microscopic and neuropathological study. Case report. J Neurosurg 85:701-708, 1996

7. Blount JP, Severson M, Atkins V, Tubbs RS, Smyth MD, Wellons JC, et al: Sports and pediatric cerebrospinal fluid shunts: who can play? Neurosurgery 54:1190-1198, 2004

8. Bondurant CP, Jimenez DF: Epidemiology of cerebrospinal fluid shunting. Pediatr Neurosurg 23:254-259, 1995

9. Borjeson MC, Lagergren J: Life conditions of adolescents with myelomeningocele. Dev Med Child Neurol 32:698-706, 1990

10. Boynton BR, Boynton CA, Merritt TA, Vaucher YE, James HE, Bejar RF: Ventriculoperitoneal shunts in low birth weight infants with intracranial hemorrhage: neurodevelopmental outcome. Neurosurgery 18:141-145, 1986

11. Callaway GH, O'Brien SJ, Tehrany AM: Chiari I malformation and spinal cord injury: cause for concern in contact athletes? Med Sci Sports Exerc 28:1218-1220, 1996

12. Cantu R, Micheli L: Guidelines for the Team Physician. Malvern, PA: Lea \& Febinger, 1991

13. Cantu RC: Epilepsy and athletics. Clin Sports Med 17:61-69, 1998

14. Cantu RC: Return to play guidelines after a head injury. Clin Sports Med 17:45-60, 1998

15. Carmont MR, Mahattanakul W, Pigott T: Acquisition of a chronic subdural haematoma during training for competitive race walking? Br J Sports Med 36:306-307, 2002

16. Cate IM, Kennedy C, Stevenson J: Disability and quality of life in spina bifida and hydrocephalus. Dev Med Child Neurol 44: 317-322, 2002

17. Chamelian L, Reis M, Feinstein A: Six-month recovery from mild to moderate Traumatic Brain Injury: the role of APOE- $\epsilon 4$ allele. Brain 127:2621-2628, 2004
18. Chiang MF, Chang JG, Hu CJ: Association between apolipoprotein $\mathrm{E}$ genotype and outcome of traumatic brain injury. Acta Neurochir (Wien) 145:649-653, 2003

19. Clear D, Chadwick DW: Seizures provoked by blows to the head. Epilepsia 41:243-244, 2000

20. Contursi S: Valero (14-0, 14 KOs) fights despite U.S. ban, in ESPN News (http://sports.espn.go.com/sports/boxing/news/ story?id=211597) [Accessed 18 August 2006]

21. Corder EH, Saunders AM, Strittmatter WJ, Schmechel DE, Gaskell PC, Small GW, et al: Gene dose of apolipoprotein E type 4 allele and the risk of Alzheimer's disease in late onset families. Science 261:921-923, 1993

22. Corsellis JA, Bruton CJ, Freeman-Browne D: The aftermath of boxing. Psychol Med 3:270-303, 1973

23. Crawford DR, Suzuki T, Sesay J, Davies KJ: Analysis of gene expression following oxidative stress. Methods Mol Biol 196: 155-162, 2002

24. Dale GE, Leigh PN, Luthert P, Anderton BH, Roberts GW: Neurofibrillary tangles in dementia pugilistica are ubiquitinated. J Neurol Neurosurg Psychiatry 54:116-118, 1991

25. Demetriades AK, McEvoy AW, Kitchen ND: Subdural haematoma associated with an arachnoid cyst after repetitive minor heading injury in ball games. Br J Sports Med 38: E8, 2004

26. Dossing M: Effect of acute and chronic exercise on hepatic drug metabolism. Clin Pharmacokinet 10:426-431, 1985

27. Dyste GN, Menezes AH, VanGilder JC: Symptomatic Chiari malformations. An analysis of presentation, management, and long-term outcome. J Neurosurg 71:159-168, 1989

28. Eriksen HR, Ellertsen B, Gronningsaeter H, Nakken KO, Loyning Y, Ursin H: Physical exercise in women with intractable epilepsy. Epilepsia 35:1256-1264, 1994

29. Esquivel E, Chaussain M, Plouin P, Ponsot G, Arthuis M: Physical exercise and voluntary hyperventilation in childhood absence epilepsy. Electroencephalogr Clin Neurophysiol 79: $127-132,1991$

30. Fountain NB, May AC: Epilepsy and athletics. Clin Sports Med 22:605-616, 2003

31. Frenkl R, Gyore A, Meszaros J, Szeberenyi S: A study of the enzyme inducing effect of physical exercise in man. The "trained liver". J Sports Med Phys Fitness 20:371-376, 1980

32. Friedman G, Froom P, Sazbon L, Grinblatt I, Shochina M, Tsenter J, et al: Apolipoprotein E- $€ 4$ genotype predicts a poor outcome in survivors of traumatic brain injury. Neurology 52: 244-248, 1999

33. Gates JR, Spiegel RH: Epilepsy, sports and exercise. Sports Med 15:1-5, 1993

34. Gotze W, Kubicki S, Munter M, Teichmann J: Effect of physical exercise on seizure threshold (investigated by electroencephalographic telemetry). Dis Nerv Syst 28:664-667, 1967

35. Graham DI, Gentleman SM, Lynch A, Roberts GW: Distribution of beta-amyloid protein in the brain following severe head injury. Neuropathol Appl Neurobiol 21:27-34, 1995

36. Hauser T: Boxing's medical mess, in Bernath $\mathrm{C}$ (ed): Secondsout.com. (http: //www.secondsout.com/usa/colhauser. $\mathrm{cfm} ? \mathrm{ccs}=208 \& \mathrm{cs}=13484$ ) [Accessed 18 August 2006]

37. Howard GM, Radloff M, Sevier TL: Epilepsy and sports participation. Curr Sports Med Rep 3:15-19, 2004

38. Iole K: Barrera: 'The truth has set him free,' in Tiger Boxing. (http://www.tigerboxing.com/articles/index.php?aid=1001244 770) [Accessed 18 August 2006]

39. Jordan BD, Relkin NR, Ravdin LD, Jacobs AR, Bennett A, Gandy S: Apolipoprotein $\mathrm{E} \epsilon 4$ associated with chronic traumatic brain injury in boxing. JAMA 278:136-140, 1997

40. Katzman R, Galasko DR, Saitoh T, Chen X, Pay MM, Booth A, et al: Apolipoprotein- $\epsilon 4$ and head trauma: synergistic or additive risks? Neurology 46:889-891, 1996

41. Kawanishi A, Nakayama M, Kadota K: Heading injury precipitating subdural hematoma associated with arachnoid cyststwo case reports. Neurol Med Chir 39:231-233, 1999 
42. Keller TM, Holland MC: Chronic subdural haematoma, an unusual injury from playing basketball. Br J Sports Med 32: 338-339, 1998

43. Kerr ME, Kraus M, Marion D, Kamboh I: Evaluation of apolipoprotein $\mathrm{E}$ genotypes on cerebral blood flow and metabolism following traumatic brain injury. Adv Exp Med Biol 471:117-124, 1999

44. Kutner KC, Erlanger DM, Tsai J, Jordan B, Relkin NR: Lower cognitive performance of older football players possessing apolipoprotein E $\epsilon 4$. Neurosurgery 47:651-658, 2000

45. Lee ST, Lui TN: Early seizures after mild closed head injury. J Neurosurg 76:435-439, 1992

46. Lee ST, Lui TN, Wong CW, Yeh YS, Tzaan WC: Early seizures after moderate closed head injury. Acta Neurochir (Wein) 137:151-154, 1995

47. Lee ST, Lui TN, Wong CW, Yeh YS, Tzuan WC, Chen TY, et al: Early seizures after severe closed head injury. Can J Neurol Sci 24:40-43, 1997

48. Lichtman SW, Seliger G, Tycko B, Marder K: Apolipoprotein $\mathrm{E}$ and functional recovery from brain injury following postacute rehabilitation. Neurology 55:1536-1539, 2000

49. Makela JP: Arnold-Chiari malformation type I in military conscripts: symptoms and effects on service fitness. Mil Med 171:174-176, 2006

50. Martinot A, Hue V, Leclerc F, Vallee L, Closset M, Pruvo JP: Sudden death revealing Chiari type 1 malformation in two children. Intensive Care Med 19:73-74, 1993

51. McCrory P: Cavum septi pellucidi-a reason to ban boxers? Br J Sports Med 36:157-161, 2002

52. Milhorat TH, Chou MW, Trinidad EM, Kula RW, Mandell M, Wolpert C, et al: Chiari I malformation redefined: clinical and radiographic findings for 364 symptomatic patients. Neurosurgery 44:1005-1017, 1999

53. Nakken KO: Physical exercise in outpatients with epilepsy. Epilepsia 40:643-651, 1999

54. Nakken KO, Bjorholt PG, Johannessen SI, Loyning T, Lind E: Effect of physical training on aerobic capacity, seizure occurrence, and serum level of antiepileptic drugs in adults with epilepsy. Epilepsia 31:88-94, 1990

55. Nakken KO, Loyning A, Loyning T, Gloersen G, Larsson PG: Does physical exercise influence the occurrence of epileptiform EEG discharges in children? Epilepsia 38:279-284, 1997

56. Nicoll JA, Roberts GW, Graham DI: Apolipoprotein E epsilon 4 allele is associated with deposition of amyloid beta-protein following head injury. Nat Med 1:135-137, 1995

57. Ogunyemi AO, Gomez MR, Klass DW: Seizures induced by exercise. Neurology 38:633-634, 1988

58. Parsch CS, Krauss J, Hofmann E, Meixensberger J, Roosen K: Arachnoid cysts associated with subdural hematomas and hygromas: analysis of 16 cases, long-term follow-up, and review of the literature. Neurosurgery 40:483-490, 1997

59. Pillay PK, Awad IA, Little JR, Hahn JF: Symptomatic Chiari malformation in adults: a new classification based on magnetic resonance imaging with clinical and prognostic significance. Neurosurgery 28:639-645, 1991

60. Pitas RE, Ji ZS, Weisgraber KH, Mahley RW: Role of apolipoprotein $\mathrm{E}$ in modulating neurite outgrowth: potential effect of intracellular apolipoprotein E. Biochem Soc Trans 26: 257-262, 1998

61. Pittella JE, Gusmao S: Cleft cavum of the septum pellucidum in victims of fatal road traffic accidents: a distinct type of cavum associated with severe diffuse axonal injury. Surg Neurol 63 (Suppl 1): S30-S35, 2005

62. Prabhu VC, Bailes JE: Chronic subdural hematoma complicating arachnoid cyst secondary to soccer-related head injury: case report. Neurosurgery 50:195-198, 2002

63. Raschka C, Weber R, Draf W: [Frontal sinus impression fracture as a collision sequelae in football.] Sportverletz Sportschaden 8:46-49, 1994 (Ger)
64. Roberts GW, Allsop D, Bruton C: The occult aftermath of boxing. J Neurol Neurosurg Psychiatry 53:373-378, 1990

65. Roberts GW, Gentleman SM, Lynch A, Murray L, Landon M, Graham DI: Beta amyloid protein deposition in the brain after severe head injury: implications for the pathogenesis of Alzheimer's disease. J Neurol Neurosurg Psychiatry 57: 419-425, 1994

66. Robinson R: Congenital cysts of the brain: arachnoid malformations. Progr Neurosurg 4:133-174, 1971

67. Saunders AM, Strittmatter WJ, Schmechel D, George-Hyslop $\mathrm{PH}$, Pericak-Vance MA, Joo SH, et al: Association of apolipoprotein E allele epsilon 4 with late-onset familial and sporadic Alzheimer's disease. Neurology 43:1467-1472, 1993

68. Schmitt B, Thun-Hohenstein L, Vontobel H, Boltshauser E: Seizures induced by physical exercise: report of two cases. Neuropediatrics 25:51-53, 1994

69. Schwidde JT: Incidence of cavum septi pellucidi and cavum vergae in 1,032 human brains. AMA Arch Neurol Psychiatry 67:625-632, 1952

70. Sorbi S, Nacmias B, Piacentini S, Repice A, Latorraca S, Forleo P, et al: ApoE as a prognostic factor for post-traumatic coma. Nat Med 1:852, 1995

71. Sosin DM, Sniezek JE, Thurman DJ: Incidence of mild and moderate brain injury in the United States, 1991. Brain Inj 10: 47-54, 1996

72. Spillane JD: Five boxers. Br Med J 2:1205-1210, 1962

73. Starkman SP, Brown TC, Linell EA: Cerebral arachnoid cysts. J Neuropathol Exp Neurol 17:484-500, 1958

74. Stephenson LA, Kolka MA, Wilkerson JE: Metabolic and thermoregulatory responses to exercise during the human menstrual cycle. Med Sci Sports Exerc 14:270-275, 1982

75. Teasdale GM, Nicoll JA, Murray G, Fiddes M: Association of apolipoprotein E polymorphism with outcome after head injury. Lancet 350:1069-1071, 1997

76. Tokuda T, Ikeda S, Yanagisawa N, Ihara Y, Glenner GG: Reexamination of ex-boxers' brains using immunohistochemistry with antibodies to amyloid beta-protein and tau protein. Acta Neuropathol 82:280-285, 1991

77. Tomaszek DE, Tyson GW, Bouldin T, Hansen AR: Sudden death in a child with an occult hindbrain malformation. Ann Emerg Med 13:136-138, 1984

78. Tsuzuki N, Katoh H, Ohtani N: Chronic subdural hematoma complicating arachnoid cyst secondary to soccer-related head injury: case report. Neurosurgery 53:242-243, 2003

79. Uhl G, McKinney M, Hedreen J: Dementia pugilistica: loss of basal forebrain cholinergic neurons and cortical cholinergic markers. Ann Neurol 12:99, 1982

80. van Linschoten R, Backx FJ, Mulder OG, Meinardi H: Epilepsy and sports. Sports Med 10:9-19, 1990

81. Vigil DV, DiFiori JP, Puffer JC, Peacock WJ: Arachnoid cyst and subdural hygroma in a high school football player. Clin $\mathbf{J}$ Sport Med 8:234-237, 1998

82. Wolf DA, Veasey SP III, Wilson SK, Adame J, Korndorffer WE: Death following minor head trauma in two adult individuals with the Chiari I deformity. J Forensic Sci 43:1241-1243, 1998

83. Ziegler DK, Mallonee W: Chiari-1 malformation, migraine, and sudden death. Headache 39:38-41, 1999

84. Zimmerman R, Jordan B: Neuroradiology of boxing injuries, in Jordan B (ed): Medical Aspects of Boxing. Boca Raton, FL: CRC Publishing, 1993, pp 188-196

Manuscript received August 7, 2006.

Accepted in final form September 7, 2006.

Address reprint requests to: Vincent J. Miele, M.D., Department of Neurosurgery, West Virginia University School of Medicine, P.O. Box 9183, Morgantown, West Virginia 26506-9183. email: lesvin@adelphia.net. 